УДК 94.(571)

ББК 63.3 (253)531

\title{
Характеристика документов личного происхождения по истории сибирского купечества второй половины XIX - начала XX в.
}

Н.Ю. Колокольцева

Алтайский государственный университет (Барнаул, Россия)

\section{Characteristics of Documents of Personal Origin on the History of Siberian Merchants in the Second Half of the $19^{\text {th }}-$ Early $20^{\text {th }}$ Centuries}

\author{
N.Y. Kolokolceva
}

Altai State University (Barnaul, Russia)

Рассматриваются особенности создания источников личного происхождения второй половины XIX - начала XX в. Центральным является вопрос о видовом разнообразии источников. Определен круг исследовательских задач, которые могут быть решены с привлечением источников. При характеристике документов личного происхождения выявлены информационные возможности, аргументировано доказано, что при всей субъективности содержания источника он позволяет произвести полную историческую реконструкцию социальной истории рассматриваемого периода.

Обозначены терминологические расхождения при работе с данной группой источников. Были проанализированы источниковедческие исследования ведущих историков по вопросу классификации источников личного происхождения. Охарактеризована специфика формирования источников купеческого происхождения во второй половине XIX - начале XX в. Данная социальная группа ни в предшествующий, ни в последующий периоды не отличалась таким количеством попыток фиксирования исторической памяти, что является отображением глубоких кризисных процессов в социальной сфере. Это попытки определения своего места в России пореформенного периода.

Ключевые слова: источниковедение, купечество, Сибирь, документы личного происхождения.

\section{DOI 10.14258/izvasu(2019)6-09}

В процессе проведения исторических исследований ведущую роль играет источниковая база. Во второй половине XIX - начале XX в. в Сибири «хозяевами жизни» называли представителей купеческого сословия.
The article discusses the features of the creation of sources of personal origin in the second half of the $19^{\text {th }}-$ early $20^{\text {th }}$ centuries. The issue of the species diversity of sources is central. The range of research tasks that can be solved with their involvement is defined. When characterizing documents of personal origin, information possibilities are revealed, it is argued that despite the subjectivity of the source content, it allows to make a complete historical reconstruction of the social history of the period under consideration. Terminological differences are indicated when working with this group of sources. The source studies of leading historians on the classification of sources of personal origin were analyzed. The specificity of the formation of sources of merchant origin in the second half of the $19^{\text {th }}-$ early $20^{\text {th }}$ centuries is characterized. This social group neither in the previous nor in the subsequent period differed in such a number of attempts to fix historical memory, which is a reflection of deep, crisis processes in the social sphere. These are attempts to determine their place in Russia post-reform period. These are attempts to determine their place in Russia post-reform period.

Key words: source studies, merchants, Siberia, documents of personal origin.

Стоит отметить, что при всей неоднозначности отношения современников к представителям данного сословия доминировали негативные оценки купца, его образа жизни и деятельности. Официальные источ- 
ники законодательного, делопроизводственного характера не позволяют исследователю с высокой степенью исторической достоверности реконструировать образ представителя того или иного сословия. Наиболее полную, хотя и субъективную информацию дают источники личного происхождения, за которыми стоит эмоциональное, но «живое» восприятие действительности. Наша задача - охарактеризовать документы личного происхождения по истории сибирского купечества второй половины XIX - начала XX в. с целью выявления их информационных возможностей.

О большом значении документов личного происхождения, которые первоначально не объединялись в единую группу, а подразделялись на мемуары, дневники, заметки, эпистолярное наследие, говорилось уже в XIX в. Был собран значительный массив источников данного типа $[1,2]$.

Мемуаристика зародилась в России в XVIII в., пройдя путь от обычного описания событий до осознания мемуаристом своей роли в истории, отдельном событии в жизни региона, а иногда и страны в целом.

Отличительной чертой документов личного происхождения является их субъективный характер. Любые внешние изменения, происходящие вокруг человека, влекут за собой изменение его позиций, ценностных ориентиров. Вторая половина XIX начало XX в. - сложная эпоха в истории России, сопровождавшаяся становлением капитализма в экономике и началом некоторых изменений в области политики, что было связано прежде всего с ростом влияния нового социального образования - класса буржуазии, основу которого в Сибири составляло купечество. Историки отмечают, что во второй половине XIX в. формировался новый комплекс источников - купеческие мемуары.

Данное увлечение не стало всеобщим, так как требовало определенного уровня грамотности, а главное - внутреннего осознания необходимости написания воспоминаний. Это во многом объясняет немногочисленность купеческих мемуаров, особенно в Сибири, где купечество отличалось более низким уровнем грамотности.

Исследователи отмечают, что авторы при написании воспоминаний использовали приемы художественной литературы [3]. Воспоминания, в силу законов жанра, создаются в зрелом возрасте, а чаще всего в преклонном, что позволяет использовать жизненный опыт для осознания всего произошедшего и происходящего. Во второй половине XIX - начале XX в. данное условие было реализовано в меньшей степени. Мемуары создавались для широкой аудитории, в отличие от источников XVIII в., которые представляли собой внутрисемейное наследие. Их ценность, своеобразие оцениваются через десятилетия, так как это во многом источник информации для последующих поколений.
Л. Левицкий, один из исследователей мемуарной литературы, подчеркивал: «Мемуарист всегда, решительно во всех случаях... передает факты субъективно... Ваше право что-то из этих мемуаров использовать, в чем-то разойтись, но не требуйте от автора, чтобы он перестал быть самим собой, чтобы он отказался от своего опыта, своих пристрастий, своего видения мира и людей» $[4$, с. 28]. Историческая достоверность, тематика, полнота источника зависят исключительно от субъекта, его творца. С.С. Минц отмечала: «Пока над мемуаристом довлела его принадлежность к сословию или определенной группе, пока его устраивала принятая в обществе система норм и ценностей и не устраивали только какието отдельные моменты, невыгодные лично для него повороты событий, повлиявших непосредственно на его судьбу, в источниках преобладала тяга к показу преимущественно событийной стороны жизни мемуариста, а не его внутреннего мира» [5, с. 39].

Изменения, происходившие в стране в исследуемый период, по-разному влияли на отдельные социальные группы. В мемуарах присутствует критика существующих порядков, ставятся сложные, подчас философские вопросы, ответа на которые мемуарист не дает, он провоцирует общество задуматься над ними. Мемуары из источника, призванного осмысливать историческое прошлое, превращаются в источник, обсуждающий вопросы настоящего и будущего. «Никогда и никто не стал бы писать своих записок, ежели был совершенно убежден, что не только при его жизни, но и по смерти ни один смертный их не прочтет и не увидит» [3, с. 14]. Но следует согласиться с Е.В. Тарле, что «коренная черта всей мемуарной литературы заключается в том, что у автора есть совершенно сознательное намерение показать читателю людей и их поступки лишь в известном освещении: выявить одно, скрыть другое, извратить третье» [5, с. 39]. При этом не следует отождествлять «субъективную природу мемуаров» с «субъективизмом оценок». Субъективность источника не означает, что он не может быть использован для реконструкции образов прошлого. Задача исследователя - установить степень искаженности информации автором на основе сопоставления с другими источниками.

Субъективизм мемуарной литературы может выражаться в эгоцентричности, когда все внимание уделяется исключительно личности автора, преувеличиваются его заслуги, степень влияния на определенные события. Таким образом, субъективизм, как и субъективность, присущи рассматриваемому виду источников, но не могут отождествляться. Если субъективность мемуаров - понятие a priori, то их субъективизм требует доказательности со стороны исследователя.

Мемуары второй половины XIX - начала $\mathrm{XX}$ в. объединяют черты художественной литера- 
туры и документализации. «Образное восприятие, стремление мемуариста облечь изложение в художественную форму не обязательно лишает источник исторической достоверности. Беллетризация не недостаток...» [5, с. 61]. Стремление мемуаристов указанного периода вызвать потомков на диалог поднимает вопрос об особой системе коммуникации, понять которую должен исследователь. Прямого диалога нет, но он подразумевается, иногда именно для этого мемуаристы и создавали свои произведения. С.О. Шмидт отмечает, что исследователь призван освоить современные источнику системы коммуникации, попытаться расшифровать и оценить источник с точки зрения его современника и в то же время прочитать его «свежим, нынешним взглядом» [6, с. 43]. Каждая эпоха имеет свою систему знаков, которую необходимо понять и расшифровать, только это способствует пониманию скрытой информации, содержащейся в мемуарах. Это задачи, которые ставит перед собой герменевтика.

Отечественная наука не делит мемуары на виды, но выделяет автобиографии и дневники, которые имеют самостоятельное значение. Главным критерием отличия являются адресность и цель создания документа. Дневники, в отличие от мемуаров, создаются для личного пользования с целью отображения событий, произошедших в недавнем прошлом. Максимально сокращен срок между событиями, о которых идет речь, и временем их описания в дневнике. Дневники могли использоваться в качестве основы для будущих мемуаров, так как в них представлена фактическая информация, которая автором по истечении времени будет осмыслена и проанализирована. В отличие от мемуаров, дневники не имеют различных редакций, их главная цель - фиксирование информации, поэтому часть исследователей склонны рассматривать их как наиболее достоверный источник из документов личного происхождения.

Дневники относятся к автокоммуникативным источникам. Однако всестороннее увлечение написанием дневников представителями различных социальных групп приходится на вторую половину XIX — начало $\mathrm{XX}$ в., что часто рассматривалось как атрибут принадлежности к высшему сословию, особый уровень грамотности. Это дает основание для утверждения о том, что многие авторы подразумевали некоторую публичность своих записей в будущем, поэтому они представляли события с выгодной для себя позиции.

Дневники как вид документов личного происхождения к изучаемому периоду претерпели изменения в меньшей степени. Во второй половине XIX - начале XX в. стало возможно редактирование дневников перед их публикацией, внесение новых сведений, что фактически сложно выявить. Это приближает дневники к мемуарам. Восприятие событий непосредственно в момент их свершения и по исте- чении некоторого промежутка времени совершенно различно. Опубликованные дневники требуют всестороннего анализа со стороны исследователя [7-9]. Многие дневники стали основой для написания воспоминаний [10], но сам факт создания дневников является признаком формирования нового типа социального сознания, изменения мировоззрения.

В отдельный вид документов личного происхождения нами выделены мемуары-автобиографии, имеющие отличие от мемуаров-воспоминаний [11-14].

Работа над автобиографиями требует серьезного анализа, осмысления собственного жизненного пути, осознания необходимости создания подобного труда. Здесь часто понятие «субъективность» подменяется «субъективизмом», прежде всего в оценочных суждениях.

В XIX в. число мемуаров-автобиографий сокращается, они все более приближаются к воспоминаниям, где повествование может быть не столь последовательно, автор позволяет себе представить в качестве главной сюжетной линии не историю собственной жизни, а людей, его окружающих.

Купеческие автобиографии в России в указанный период - явление редкое, вызывавшее живой интерес, особенно «работы провинциалов и новичков, которыми пополнялся торгово-промышленный класс в 50-60-е годы» [15, с. 112]. К источникам подобного характера относятся автобиографические воспоминания Н.М. Чукмалдина [14] и И.В. Кулаева [12].

«Записки о моей жизни» Н.М. Чукмалдина - повествование о становлении личности, сложной судьбе человека из народа, достигшего значительных высот. Автор не претендовал на объективность своего изложения, описал один из способов вхождения в купеческое сословие, его внутреннюю жизнь, ценности, различия, существовавшие между провинциальной и столичной жизнью. Своеобразие воспоминаний H.M. Чукмалдина в том, что он попытался взглянуть на купечество одновременно изнутри и со стороны, выступая с критикой норм, существовавших в этой среде.

Купечество было мобильным сословием, которое пополнялось за счет притока людей из различных социальных групп, наиболее часто из крестьянства, что и сближало в общих чертах образ жизни купца и крестьянина. Автор происходил из крестьянской семьи, прошел путь от подручного приказчика, продавца в лавке до вступления в купеческую гильдию.

Положительным моментом работы является отсутствие попыток идеализировать купечество. Автор рисует портреты различных купцов, описывая их происхождение, путь к гильдии и методы ведения дела. При этом он не пытается навязать собственные оценки, несмотря на то, что симпатии и антипатии автора ясно определяются исходя из повествования.

Мемуары являются итогом размышлений автора о специфике российской экономики и причинах 
ее сложного развития, о взаимоотношениях между людьми в провинции, которые основаны на принципах доверия и уважения, и в столичных городах, где личная выгода ставится выше понятий дружбы, взаимовыручки, чести. Жизнь сословия изображена на фоне сложной исторической ситуации, что позволяет исследователю более детально изучить эпоху.

История жизни Ивана Васильевича Кулаева представляет собой жизнь страны в миниатюре. Жизненные позиции автора определили манеру написания мемуаров и наиболее полно воплотились в выборе их названия: «Под счастливой звездой». И.В. Кулаев относился к предпринимателям нового поколения, обладавшего определенным уровнем грамотности, четко ставившего цель и знавшего способы ее достижения.

В российском обществе было распространено мнение, что большие капиталы - это результат нечестных действий. И.В. Кулаев, описывая предприятия, как собственные, так и ряда лиц, игравших значительную роль в экономике Сибири и России (3.М. Цыбульского, И.М. Иваницкого, М.Д. Бутина, В.Н. Мичкова и др.), доказывал, что не все столь однозначно. И.В. Кулаев поднимал вопрос о взаимоотношениях предпринимателей и государства, которое было готово учитывать только свои интересы, без должного внимания к новому социальному образованию и его поддержки. Приход к власти большевиков в 1917 г., национализация собственности и капиталов в очередной раз разорили Ивана Васильевича, который покинул Россию.

Следующей группой источников является эпистолярное наследие [16-18]. Частная переписка - результат взаимодействия двух людей, она не предназначена для третьих лиц. Некоторая закрытость источника позволяет авторам более открыто выражать свои мысли и чувства. Ко второй половине XIX - началу XX в. активность частной переписки возрастает, при этом она становится более демократичной. В XVIII - первой половине XIX в. ведение переписки - признак принадлежности к высшему сословию. Во второй половине XIX в. в качестве адресата выступают представители различных социальных групп — от разночинцев до буржуазии. Четко сформированный эпистолярный этикет стал более либеральным. Все атрибуты письма были сохранены: указание адресата, даты и места написания, подпись автора, но функциональное назначение изменилось. Для понимания значимости источника важна работа не с отдельным письмом, а изучение переписки в целом, что позволяет более точно установить характер взаимоотношений между адресатами.

Наиболее приближенной по стилю к художественной литературе группой источников являются литературные заметки. Мемуаристы прибегали к литературным приемам с целью придания своей работе четкой формы, чтобы сделать ее более понятной широкой аудитории. Подобные приемы использовались теми авторами, которые изначально создавали свои произведения для печати.

Субъективный характер документов личного происхождения требует глубокой источниковедческой критики. Важной задачей является установление авторства, выявление его личностных характеристик: годы жизни, возраст, в котором произведение было создано, пол, социальная принадлежность, профессиональные интересы, общественно-политические взгляды, роль, которую автор играл в обществе. Эта информация часто латентно содержится прежде всего в мемуарах, но так как она исходит собственно от автора, то необходима ее проверка по другим источникам. Во второй половине XIX в. рост числа мемуаристов приводит к тому, что исследователю сложно установить личностные характеристики автора, поскольку часто сведения о них по другим источникам отсутствуют.

Следующей задачей становится определение времени написания мемуаров и периода, о котором идет речь. Увеличение временного промежутка между этими этапами приводит к ошибкам памяти, которые могут быть не намеренными. Необходимо рассматривать историческую действительность, в которой создавались мемуары. Исследователь обязан изучить эпоху, присущую ей систему ценностей, в противном случае «диалог» между мемуаристом и потомками невозможен.

Купечество, подражая представителям высших сословий, оставляло потомкам мемуары. Во второй половине XIX - начале XX в. побудительным мотивом могла стать внутренняя необходимость осмысления собственного жизненного пути, определение своего места в исторической действительности. Неизменным остается факт, что все мемуаристы подразумевали, вне зависимости от цели написания воспоминаний, что они могут быть опубликованы, следовательно, их увидит широкая аудитория. Мемуарист вправе уделять внимание тем вопросам, которые в большей степени влияли на его жизнь. Исследователь не может ставить это в вину автору, он должен определить причины, побудившие мемуариста обратиться именно к этой теме.

Одним из приемов источниковедческой критики является сравнение различных редакций мемуаров, что способствует выявлению наиболее полного варианта. Данный метод вызывает затруднения относительно указанного периода, так как мемуаристы публиковали свои работы в сжатые сроки, чаще всего в журналах и отдельными отрывками. Критика источников в целом очень трудна, особенно в вопросах бытописания, взаимоотношений внутри социальной группы.

Основу внутренней критики составляет работа с текстом. Определяются форма, манера, стиль письма автора, что может способствовать, в том числе, опре- 
делению его личностных характеристик. Необходимо сопоставление информации, содержащейся в документах личного происхождения, с другими источниками, отображающими данные события. Факты сопоставляются, выявившиеся отличия анализируются, однако определение причины расхождения информации не всегда возможно, как и подтверждение степени достоверности параллельного источника.

Подобные методы критики применяются в целом для документов личного происхождения, но есть своя специфика при работе с материалами переписки. Не вызывает сложности определение адресата и даты написания письма, что является необходимым атрибутом данной формы сообщения, чаще сложности связаны с определением авторства письма. По эпистолярному этикету письмо должно иметь указание на автора, что выражается в наличии автографа, установление личностной принадлежности которого не всегда возможно. Для деловой переписки подобные сложности не характерны. При частной переписке письмо - это взаимоотношения двух людей, и полное указание авторства считалось не обязательным. Возникает вопрос о возможности всестороннего использования материалов частной переписки, насколько данный шаг соответствует нормам этики.

В то же время при работе с перепиской исследователю не составляет труда выявить цели написания письма, так как оно создается при конкретных обстоятельствах. Если мемуары являются законченным произведением, то переписка часто отрывочна, что не дает возможности изучения ее в целом.
Таким образом, документы личного происхождения второй половины XIX - начала XX в. имели более демократичный и в то же время более публичный характер по сравнению с источниками XVIII — первой половины XIX в. Своеобразие информации, содержащейся в них, не позволяло исследователям долгое время однозначно оценить их возможности. Возросший интерес к мемуарному наследию стал результатом осознания того, что именно они содержат уникальную информацию о внутреннем мире человека, социальной группе, стране, без чего невозможно объективное понимание исторического процесса. Увлеченность купцов написаниями мемуаров, ведением дневников, длительных частных переписок - результат заимствования, точнее, копирования, образа жизни дворянского сословия, место которого в обществе они пытались занять, переборов тем самым отношение к себе как к «выскочкам» из народа. Это сословие вызывало к себе живой интерес современников [19].

Источники личного происхождения корректируют наши представления о сибирском купечестве и образы, созданные в исследовательской литературе. Они демонстрируют невозможность однозначных суждений. Если купец был недостаточно образован, не следовал общепринятым нормам поведения, то это не означало, что он плохой торговец, для которого важна только личная выгода, без учета общественных настроений и наоборот. Свидетельства источников не могут восприниматься как истинные вне зависимости от авторства и содержания, без детального анализа.

\section{Библиографический список}

1. Минцлов С.Р. Обзор записок, дневников, воспоминаний, писем и путешествий, относящихся к истории России и напечатанных на русском языке. Вып 4-5. Новгород, 1912.

2. История дореволюционной России в дневниках и воспоминаниях. Аннотированный указатель книг и публикаций в журналах. Т. I-V. М., 1977-1989.

3. Тартаковский А.Г. Русская мемуаристика XVIII первой половины XIX вв. : от рукописи к книге. М., 1991.

4. Гаранин Л.Я. Мемуарный жанр советской литературы : историко-теоретический очерк. Минск, 1986.

5. Минц С.С. Об отражении особенностей социальной психологии в мемуарных источниках последней трети XIX в. // Проблемы источниковедения истории СССР и специальных исторических дисциплин. М., 1984.

6. Шмидт С.О. Современные проблемы источниковедения // Источниковедение. Теоретические и методологические проблемы. М., 1969.

7. Вагин В.И. Дневник // Сибирь. 1980. № 3, 5.
8. Забелин И.Е. Дневники. Записные книжки. М., 2001. 384 c.

9. [Ленивцев А.] Из моего дневника // Отечественные записки. 1862. Февраль.

10. Сибирский купец А.Д. Васенев / сост. А.В. Старцев : в 2 ч. Барнаул, 1994.

11. Елпатьевский С.Я. Воспоминания за 50 лет. Уфа, 1984.

12. Кулаев И.В. Под счастливой звездой. Воспоминания. М., 1999.

13. Попов И.И. Минувшее и пережитое. Воспоминания за 50 лет. Сибирь и эмиграция. Л., 1924.

14. Чукмалдин Н.М. Записки о моей жизни. М., 1902.

15. Кафенгауз Б.Б. Купеческие мемуары // Московский край в его прошлом. М., 1928.

16. Клевакин Е. Барнаульские письма // Алтай. 1996. № $1-2$.

17. Родионов И.В. Письма из городов. Из Иркутска // Сибирские отголоски. 1906. № 6.

18. Словцов П.А. Письма из Сибири. М., 1826.

19. Мемуары сибиряков. XIX в. Новосибирск, 2003. 